http://jmscr.igmpublication.org/home/ ISSN (e)-2347-176x ISSN (p) 2455-0450 crossref DOI: https://dx.doi.org/10.18535/jmscr/v8i4.40

\title{
Comparative study of effects of intrathecal Midazolam and Fentanyl in combination with $0.5 \%$ hyperbaric Ropivacaine in infra-umbilical surgeries
}

\author{
Authors \\ Dr Anil Panwar ${ }^{1 *}$, Dr S.P. Chittora ${ }^{2}$ \\ ${ }^{1}$ JR3, Department of Anaesthesiology, Jhalawar Medical College, Jhalawar \\ ${ }^{2}$ Prof. \& HOD, Department of Anaesthesiology, Jhalawar Medical College, Jhalawar \\ *Corresponding Author \\ Dr Anil Panwar \\ JR3 Dept of Anaesthesiology, Jhalawar Medical College, Jhalawar, India
}

\begin{abstract}
Aims: Comparison of intrathecal Midazolam and fentanyl with hyperbaric ropivacaine to assess duration \& quality of spinal blockade.

Method: A prospective, randomized, double-blinded study conducted on 90 patients, aged 20-60 years, ASA I \& II, undergoing infra-umbilical surgeries, into three groups given hyperbaric ropivacaine intrathecally along-with: $0.5 \mathrm{ml}$ of normal saline (group R) $0.5 \mathrm{ml}$ of $25 \mu \mathrm{g}$ fentanyl (group RF) and $0.5 \mathrm{ml}$ of $1 \mathrm{mg}$ midazolam (group RM). Onset, duration of blockade, postoperative pain, time to first rescue analgesia and side effects were noted. $P$-values < 0.05 considered significant.

Result: Demographic profile, surgery type, duration, vital parameters, onset \& duration of sensory \& motor blockade, postoperative sedation were comparable. Time to first sensation of pain was earlier in group $R(150 \pm 31 \mathrm{~min})$ than in group $R F(205 \pm 30 \mathrm{~min})$, group $R M(195 \pm 29 \mathrm{~min})$. First analgesic dose time, earlier in group $R(181 \pm 26 \mathrm{~min})$, group $R F(242 \pm 31 \mathrm{~min})$, group $R M(233 \pm 26.7 \mathrm{~min})$, faster time to two-segment regression in group $R(122 \pm 13.4 \mathrm{~min})$ compared with group $R F(162 \pm 14.8 \mathrm{~min})$, group $R M(151 \pm 16.4 \mathrm{~min})$. Nausea-vomiting in 6 cases \& pruritus in 10 cases in group $R F$.

Conclusion: Intrathecal midazolam with ropivacaine is better alternative than ropivacaine alone or with fentanyl for increasing block duration \& decreasing postoperative analgesia need.

Keywords: Midazolam, Ropivacaine, Fentanyl, intrathecal, infra-umbilical.
\end{abstract}

\section{Introduction}

Ideal spinal anaesthetic would provide rapid and adequate surgical anaesthesia together with early ambulation and early discharge. Ropivacaine is an amide local anaesthetic agent with similar local anaesthetic properties as bupivacaine. Ropivacaine has a potentially improved safety profile compared with bupivacaine. ${ }^{[1]}$

Various intrathecal adjuvants to local anaesthetics are used. When local anaesthetics are combined with opioids, duration of analgesia is prolonged. Fentanyl, a short-acting lipophilic opioid, increased the intraoperative quality of spinal anaesthesia. ${ }^{[2]}$

However, worrisome adverse effects such as pruritus, urinary retention, postoperative vomiting, and respiratory depression limits use of opioids. ${ }^{[3]}$

Midazolam is imidazobenzodiazepine which is water soluble in acid formulation but is highly lipid soluble in vivo. It has spinally mediated antinociceptive effect. ${ }^{[4]}$ 
Studies shows that intrathecal administration of midazolam added to bupivacaine improves duration and quality of spinal anaesthesia. ${ }^{[5]}$

There are no data showing effect of intrathecal midazolam when added to ropivacaine. Therefore, this study was planned to compare analgesic efficacy and safety of intrathecal midazolam and fentanyl as an adjunct to ropivacaine spinal anaesthesia in patients undergoing infra-umbilical surgeries.

\section{Materials and Methods}

This prospective, randomized study was conducted after obtaining approval from institutional ethics committee.

\section{Inclusion Criteria}

1) ASA grade I and II

2) Age 20-60 years of either sex

3) Undergoing infra-umbilical surgeries like appendicitis surgery, lower-limb surgeries.

\section{Exclusion Criteria}

1) Patients refusing consent.

2) Patients with coagulopathy disorders

3) Spinal deformity, infection at puncture site.

4) Allergy to local anaesthetics.

Study was conducted in randomized, double-blind controlled manner using closed envelope method on 90 patients were enrolled into three groups of 30 patients each:

Group R (control group) received $3 \mathrm{ml}(15 \mathrm{mg})$ of hyperbaric ropivacaine plus $0.5 \mathrm{ml}$ of normal saline,

Group RF received $3 \mathrm{ml}(15 \mathrm{mg})$ of hyperbaric ropivacaine plus $0.5 \mathrm{ml}$ of $25 \mu \mathrm{g}$ fentanyl $(50 \mu \mathrm{g} / \mathrm{ml})$ and

Group RM received $3 \mathrm{ml}(15 \mathrm{mg})$ of hyperbaric ropivacaine plus $0.5 \mathrm{ml}$ of $1 \mathrm{mg}$ midazolam (2 $\mathrm{mg} / \mathrm{ml}$ ) all making total volume of $3.5 \mathrm{ml}$ intrathecally.

Hyperbaric ropivacaine solution was prepared aseptically by adding $2.75 \mathrm{ml}$ of $0.75 \%$ ropivacaine to $1.25 \mathrm{ml}$ of $25 \%$ dextrose achieving a concentration of $0.5 \%$ hyperbaric ropivacaine $(3 \mathrm{ml}$ used out of total $4 \mathrm{ml}$ ). The study drug was prepared by an anesthesiologist not involved in patient management and data collection.
Normal saline $15 \mathrm{ml} / \mathrm{kg} / \mathrm{h}$ preloaded around $20 \mathrm{~min}$ before administration of spinal anaesthesia. Written, valid and informed consent was obtained from all patients.

Standard monitoring with five-lead ECG, NIBP at 5-min intervals, pulse oximetry connected and baseline values taken. Before starting, methods of sensory (cold test) and motor (Bromage scale) assessments were explained to patients. Spinal anaesthesia was performed in sitting position.

Sterilization of patients' back was done with povidone iodine solution $10 \%$, and then skin and subcutaneous infiltration with $2 \mathrm{ml}$ of lidocaine $1 \%$ was performed.

Spinal puncture was performed using midline approach at third to fourth lumbar interspace with 25-G Quincke spinal needle. Once free flow of cerebrospinal fluid was obtained, study drug was injected at rate of $\sim 0.2 \mathrm{ml} / \mathrm{s}$.

Sensory block (time between injection of intrathecal local anaesthetic until loss of cold sensation at level of T10) was assessed at 2 and 5 min after injection until two consecutive levels of sensory block were identical.

Surgery was started when sensory block reached T10 dermatome and at stage 2 of Bromage scale ${ }^{[6]}$

For motor blockade which was assessed every 5 minutes

Bromage $0=$ no paralysis

Bromage $1=$ unable to raise extended leg

Bromage $2=$ unable to flex knee

Bromage 3 = unable to flex ankle.

Onset and duration of sensory and motor blockade were recorded. $\mathrm{HR}, \mathrm{BP}, \mathrm{SpO}_{2}$ were recorded at baseline, after intrathecal injection, and then every 5 min until end of surgical procedure. Oxygen provided at $6 \mathrm{l} / \mathrm{min}$ through face mask during surgery. IV fluids (crystalloids, colloids, blood) administered for maintenance according to surgical blood loss.

Hypotension (MAP $<25 \%$ of baseline) and bradycardia ( $\mathrm{HR}<50$ beats/min) were treated with intravenous ephedrine $5 \mathrm{mg}$ and atropine $0.5 \mathrm{mg}$, respectively. 
All patients monitored for vital data every $2 \mathrm{~h}$ for first $8 \mathrm{~h}$ and then at 12,18, and $24 \mathrm{~h}$ postoperatively. Any adverse effects- bradycardia, hypotension, respiratory depression, pruritus, headache, and postoperative nausea vomiting was recorded. Postoperative pain was assessed by means of verbal rating pain scale $(0-10: 0=$ no pain and $10=$ worst imaginable pain) at $1 \mathrm{~h}$ intervals until requirement for supplementary analgesia arises.

Rescue analgesia was provided with intravenous diclofenac $1.5 \mathrm{mg} / \mathrm{kg}$ when VRS score was 4 or more. Duration of postoperative analgesia - time from intrathecal injection until administration of first rescue analgesia (primary outcome) - was recorded.

Sedation level was assessed every hour for $6 \mathrm{~h}$ postoperatively by Ramsay Sedation Score ${ }^{[7]}$

$1=$ anxious, agitated, and restless

$2=$ cooperative, oriented, tranquil

$3=$ responsive to commands only

4 = Patient exhibits brisk response to light glabellar tap or loud auditory stimulus

5 = Patient exhibits a sluggish response to light glabellar tap or loud auditory stimulus

$6=$ Patient exhibits no response

\section{Results}

No statistically significant differences noted between three groups in age, sex, BMI, ASA status, duration (table 1), and type of surgery (table 2) and mean arterial blood pressure.

Table 1: Demography and duration of surgery

\begin{tabular}{|l|c|c|c|c|}
\hline Variables & $\begin{array}{c}\text { Group R } \\
\text { (SD) }\end{array}$ & $\begin{array}{c}\text { Group RF } \\
\text { (SD) }\end{array}$ & $\begin{array}{c}\text { Group RM } \\
\text { (SD) }\end{array}$ & P-value \\
\hline Age & $41.5(12.6)$ & $38.7(11.3)$ & $42.6(9.8)$ & 0.534 \\
\hline Sex & F-18; & F-17; & F-11; & 0.619 \\
& M-12 & M-13 & M-19 & \\
\hline BMI & $26.4(5.7)$ & $24.7(5.1)$ & $27.8(6.2)$ & 0.234 \\
\hline ASA & I- 23; & I- 25; & I- 26; & 0.459 \\
& II- 7 & II- 5 & II- - & \\
\hline $\begin{array}{l}\text { Surgery duration } \\
\text { (minutes) }\end{array}$ & $90(12.8)$ & $95.7(15.4)$ & $99.2(13.5)$ & 0.155 \\
\hline
\end{tabular}

Table 2: Type of Surgery in three groups

\begin{tabular}{|l|c|c|c|c|}
\hline Surgery type & $\begin{array}{c}\text { Group R } \\
(30)\end{array}$ & $\begin{array}{c}\text { Group RF } \\
(30)\end{array}$ & $\begin{array}{c}\text { Group RM } \\
(30)\end{array}$ & $\begin{array}{c}\text { P- } \\
\text { value }\end{array}$ \\
\hline Pott's fracture & $3(10 \%)$ & $2(7 \%)$ & $4(13 \%)$ & 0.715 \\
\hline Fracture tibia & $6(20 \%)$ & $5(17 \%)$ & $4(13 \%)$ & 0.819 \\
\hline $\begin{array}{l}\text { Knee } \\
\text { arthroscopy }\end{array}$ & $15(50 \%)$ & $18(60 \%)$ & $17(57 \%)$ & 0.869 \\
\hline $\begin{array}{l}\text { Fracture shaft } \\
\text { femur }\end{array}$ & $6(20 \%)$ & $5(17 \%)$ & $5(17 \%)$ & 0.939 \\
\hline
\end{tabular}

Three patients out of $30(10 \%)$ in group $\mathrm{R}$, four patients out of $30(13 \%)$ in group RF, two patients out of $30(7 \%)$ in group RM developed hypotension and needed intravenous ephedrine

(Table 3)

Table 3: Intra-operative Mean arterial BP

\begin{tabular}{|l|c|c|c|c|}
\hline $\begin{array}{l}\text { Values in mean } \\
\text { (SD) }\end{array}$ & Group R & Group RF & Group RM & P-value \\
\hline Baseline MAP & $94.7(12.3)$ & $97.2(14.7)$ & $100.0(9.9)$ & 0.414 \\
\hline $\begin{array}{l}\text { Minimum } \\
\text { MAP }\end{array}$ & $83.8(6.8)$ & $82.8(6.5)$ & $85.0(2.4)$ & 0.459 \\
\hline $\begin{array}{l}\text { Ephedrine } \\
\text { needed in }\end{array}$ & 3 cases & 4 cases & 2 cases & 0.574 \\
\hline
\end{tabular}

No significant difference between groups in HR and hemodynamic stability. Three (10\%) patients in group R and group RF and two (7\%) patients in group RM developed bradycardia and received atropine (table 4).

Table 4: Intra-operative Heart Rate

\begin{tabular}{|l|l|l|l|l|}
\hline $\begin{array}{l}\text { Values in mean } \\
\text { (SD) }\end{array}$ & Group R & Group RF & Group RM & P -value \\
\hline Baseline HR & $72.9(9.7)$ & $69.6(10.8)$ & $68.2(8.3)$ & 0.285 \\
\hline Minimum HR & $69.1(5.5)$ & $67.4(4.8)$ & $66.1(6.3)$ & 0.250 \\
\hline $\begin{array}{l}\text { Atropine needed } \\
\text { in }\end{array}$ & 3 cases & 3 cases & 2 cases & 0.866 \\
\hline
\end{tabular}

No significant differences between groups in $\mathrm{SpO}_{2}$ and respiratory rate. MAP and $\mathrm{HR}$ was significantly higher in group $\mathrm{R}$ than in groups $\mathrm{RF}$ and $\mathrm{RM}$ at $2 \mathrm{~h}$ postoperatively, which is attributed to earlier sensory recovery.

No significant differences in $\mathrm{SpO}_{2}$ (none reaching $<95 \%$ ) and respiratory rate in postoperative period.

Significant difference in time to first sensation of pain, earlier in group $\mathrm{R}(150 \pm 31 \mathrm{~min})$ than in group RF (205 $\pm 30 \mathrm{~min})$ and group RM $(195 \pm 29$ $\min )$. $\mathrm{p}$ - value $=0.743$.

Time to first analgesic dose was earlier in group $\mathrm{R}$ $(181 \pm 26 \mathrm{~min})$ than in group RF $(242 \pm 31 \mathrm{~min})$ and group RM ( $233 \pm 26.7 \mathrm{~min})$. P-value $=0.564$.

Group R showed significantly faster time to twosegment regression $(122 \pm 13.4 \mathrm{~min})$ compared with group RF (162 $\pm 14.8 \mathrm{~min})$ and group RM (151 \pm $16.4 \mathrm{~min})$. P-value $=0.469$.

No significant difference regarding onset and level of sensory, motor block, and postoperative sedation. 
Figure 5: Time of sensory regression, analgesia duration

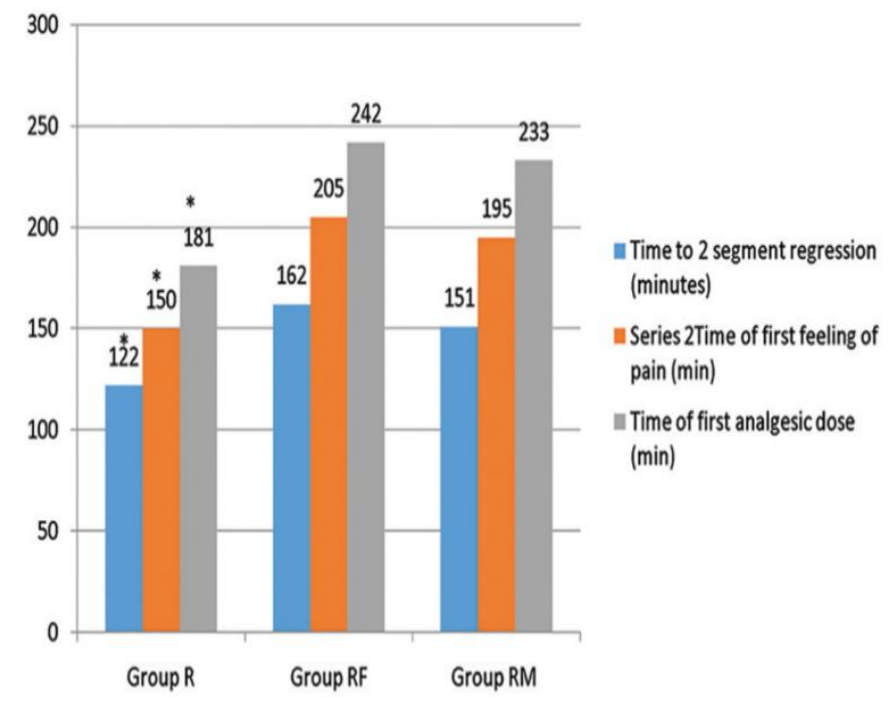

\section{Complication in three groups}

One reported case of nausea and vomiting in groups $\mathrm{R}$ and RM and six cases in group RF $(P=0.004)$. One reported case of shivering in groups RF and $\mathrm{RM}$ and two cases in group $\mathrm{R}(P=0.765)$ and 10 reported cases of pruritus in group $\mathrm{RF}$, one casein group $\mathrm{RM}$ and no cases in group $\mathrm{R}(P=0.002)$.

Figure 6: Incidence of complications in three groups

\section{Complications}

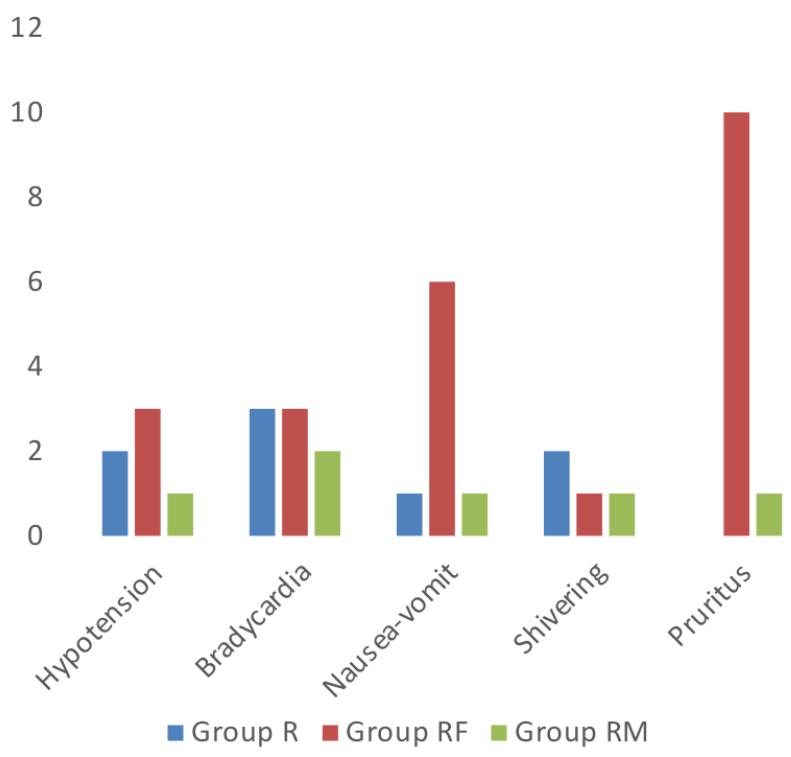

\section{Discussion}

Ropivacaine is long-acting, enantiomerically pure ( $S$-enantiomer) amide local anaesthetic with low lipid solubility that blocks nerve fibres involved in pain transmission ( $\mathrm{A} \delta$ and $\mathrm{C}$ fibres) to greater degree than those controlling motor function $(\mathrm{A} \beta$ fibres). Ropivacaine is less toxic to cardiovascular and central nervous systems than bupivacaine and approved for intrathecal administration by European Union in February 2004. ${ }^{[8]}$ Use of analgesic adjuvants has been proved very valuable in maintaining advantage of ropivacaine while improving quality of anaesthesia. ${ }^{[9]}$

This study was performed to determine optimal analgesic adjuvant with lowest possible complications. It demonstrated increased duration of sensory blockage and postoperative analgesia after subarachnoid injection of midazolam or fentanyl as adjuvant to hyperbaric ropivacaine. Analgesic effect of midazolam was same with lesser complications. Results of present study support results of Yegin et $a l^{[2]}$ that reported no clinically relevant changes in $\mathrm{BP}, \mathrm{HR}, \mathrm{SpO}_{2}$, respiratory function after intrathecal administration of fentanyl in combination with hyperbaric ropivacaine.

Previous studies assessed analgesic effects of intrathecal midazolam added to bupivacaine, and our study assessed analgesic effect of intrathecal midazolam added to hyperbaric ropivacaine. Yun et $a l .{ }^{[10]}$ also observed similar results in three groups in which one group received $11 \mathrm{mg}$ of intrathecal $0.5 \%$ hyperbaric bupivacaine alone, another received adjuvant of $1 \mathrm{mg}$ midazolam, and third received adjuvant of $2 \mathrm{mg}$ of midazolam, with no differences in hemodynamic variables among three groups. Three groups showed no significant difference regarding onset of sensory block, level of block, time and duration of motor block. Ropivacaine group showed significantly more rapid time to 2 segment regression than when combined to midazolam or fentanyl. The time to first sensation of pain was earlier with ropivacaine alone $(150 \pm 31)$ than when combined with fentanyl $(205 \pm 30)$ or midazolam (195 \pm 29$)$ and also time to first analgesic dose was earlier in patients given 
ropivacaine alone $(181 \pm 26)$ than when combined with fentanyl $(242 \pm 31)$ or midazolam (233 \pm 26.7).Results of this study agree with those of Chavda et al. ${ }^{[11]}$ and supported by Prakash et al. ${ }^{[12]}$ who conducted a study to investigate analgesic efficacy of two doses of intrathecal midazolam as adjunct to bupivacaine for spinal anaesthesia in patients undergoing caesarean delivery. They concluded that intrathecal midazolam $2 \mathrm{mg}$ provided a moderate prolongation of postoperative analgesia when used as adjunct to bupivacaine.

Sedation assessed by Ramsay Sedation Score. No patients in our study developed moderate or deep level of sedation. Bharti et al. ${ }^{[5]}$ performed study that included 40 ASA I or II adult patients undergoing lower abdominal surgery, randomly allocated to receive $3 \mathrm{ml}$ of $0.5 \%$ hyperbaric bupivacaine intrathecally either alone or with $1 \mathrm{mg}$ of midazolam using CSE technique. Sedation scores were comparable in two groups.

Regarding complications, one patient complained of nausea and vomiting in groups $\mathrm{R}$ and $\mathrm{RM}$ and six patients in group RF. Ten patients complained of pruritus in group RF in comparison with just one patient in group RM and no cases in group $\mathrm{R}$, which was statistically significant $(P<0.05)$. Shah et al. ${ }^{[13]}$ performed study comparing effect of addition of ropivacaine or bupivacaine upon pruritus induced by intrathecal fentanyl in labour and concluded that intrathecal

ropivacaine and, to a greater extent, intrathecal bupivacaine reduce incidence and severity of pruritus from intrathecal fentanyl.

\section{Statistical Analysis}

Data was analysed using Stata 12.0 (College station, TEXAS, USA). Numerical variables presented as mean $\pm \mathrm{SD}$, whereas categorical variables presented as number of cases and percentage. ANOVA used for comparison between groups as numerical variables. $\chi^{2}$-test was used to compare proportions between three qualitative parameters. Considered significant, if $P$ values $<0.05$. Sample size was calculated on basis of previous studies for detecting clinically significant difference of $30 \%$ in duration of analgesia, assuming a power of $80 \%$ and significance of $5 \%$.

\section{Conclusions}

Adding midazolam to hyperbaric ropivacaine in spinal anaesthesia is good alternative for improving duration of sensory block, decreasing analgesic requirement in early postoperative period with minimal side effects compared with hyperbaric ropivacaine alone or fentanyl combined with hyperbaric ropivacaine in spinal anaesthesia.

\section{References}

1. Arthur GR, Feldman HS, Covino BG. Comparative pharmaco-kinetics of bupivacaine and ropivacaine, a new amide local anesthetic. Anesth Analg 1988; 67:1053-1058.

2. Yegin A, Sanli S, Hadimioglu N, Akbas M, Karsli B. Intrathecal fentanyl added to hyperbaric ropivacaine for transurethral resection of the prostate. Acta Anaesthesiol Scand 2005; 49:401-405.

3. Raffaeli W, Marconi G, Fanelli G, Taddei S, Borghi GB, Casati A. Opioid-related sideeffects after intrathecal morphine: a prospective, randomized, double-blind doseresponse study. Eur J Anaesthesiol 2006; 23:605-610.

4. Nishiyama T, Hanaoka K. Midazolam can potentiate the analgesic effects of intrathecal bupivacaine on thermal- or inflammatoryinduced pain. AnesthAnalg 2003; 96:13861391.

5. Bharti N, Madan R, Mohanty PR, Kaul HL. Intrathecal midazolam added to bupivacaine improves the duration and quality of spinal anaesthesia. Acta AnaesthesiolScand 2003; 47:1101-1105.

6. Bromage PR. Epidural Analgesia. Philadelphia: WB Saunders; 1978: 144

7. Ramsay MA, Savege TM, Simpson BR, Goodwin R. Controlled sedation with alphaxolone-alphadalone. BMJ. 1974;2:656659. 
8. Wille M. Intrathecal use of ropivacaine: a review. Acta Anaesthesiol Belg 2004; 55:251-259.

9. Chhabra AR, Jagtap SR, Dawoodi SF. Comparison of clonidine versus fentanyl as an adjuvant to intrathecal ropivacaine for major lower limb surgeries: a randomized double-blind prospective study. Indian $\mathbf{J}$ Pain 2013; 27:170-174.

10. Yun MJ, Kim YH, Kim JH, Kim KO, Oh AY, Park HP. Intrathecal midazolam added to bupivacaine prolongs the duration of spinal blockade to T10 dermatome in orthopedic patients. Korean J Anesthesiol 2007; 53: S22-S28.

11. Chavda H, Mehta P, Vyas A. A comparative study of intrathecal fentanyl and sufentanil with bupivacaine heavy for postoperative analgesia. Internet J Anesthesiol 2008; 20:1.

12. Prakash S, Joshi N, Gogia AR, Prakash S, Singh R. Analgesic efficacy of two doses of intrathecal midazolam with bupivacaine in patients undergoing cesarean delivery. Reg Anesth Pain Med 2006; 31:221-226.

13. Shah MK, Sia AT, Chong JL. The effect of the addition of ropivacaine or bupivacaine upon pruritus induced by intrathecal fentanyl in labour. Anaesthesia 2000; 55:1008-1013. 